\title{
An Economic Evaluation of Electromechanical Components for Microhydro in Borneo - Case Study
}

\section{Mohd Azlan Ismail1 ${ }^{1}$ Al Khalid Othman ${ }^{2}$, Hushairi Zen ${ }^{3}$}

${ }^{1}$ Researcher, Faculty of Engineering, University Malaysia Sarawak, MALAYSIA

${ }^{2}$ Associate Professor, Faculty of Engineering, University Malaysia Sarawak, MALAYSIA

${ }^{3}$ Senior Lecturer, Faculty of Engineering, University Malaysia Sarawak, MALAYSIA

\begin{abstract}
This paper presents an economic evaluation using Life Cycle Cost Analysis and Rate of Return to compare Pump as Turbine and Multi Jet Pelton Turbine as an electromechanical component in a microhydro project for Kampung Longkongungan, Sabah. The aim of this paper is to support microhydro project managers in rural areas to evaluate economic advantages between two type of turbines, taking into account relevant cost components, covering a wider perspective beyond capital cost. The analysis is set in view of 15 years product lifespan with discount rate set at $5 \%$ per annum. The goal of this study is to determine which system produced the best return on investment. All relevant data have been collected through product manuals, product suppliers, and academic literature. The study reveals that Pump as Turbine and Multi Jet Pelton Turbine cumulative profit are recorded at MYR 10,065.11 and MYR 14,863.82 respectively. The Rate of Return for Pump as Turbine is at 4.34 while Multi Jet Pelton at 6.11 years. The result shows that Pump as Turbine has a low capital cost and shorter Rate of Return. However, due to low efficiency, the total return of investment is lower than Multi Jet Pelton Turbine.
\end{abstract}

Keywords: microhydro, electromechanical, pump as turbine, life cycle cost, rate of return
This article is is licensed under a Creative Commons AttributionNonCommercial 4.0 International License.

Attribution-NonCommercial (CC BY-NC) license lets others remix, tweak, and build upon work non-commercially, and although the new works must also acknowledge \& be noncommercial.

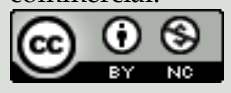
Source of Support: Centre of Excellence for Renewable Energy (CoERE), Universiti Malaysia Sarawak (UNIMAS) under Grant no. UNIMAS/CoERE/2014/Grant (01).
Conflict of Interest: None declared 


\section{INTRODUCTION}

More than 55\% of ASEAN (Association of Southeast Asian Nations) country's population live in rural areas, and has been reported that 130 million are without access to electricity. Myanmar, Cambodia, Lao PDR and Indonesia were reported to be countries having the lowest percentage of electrification coverage to the electrification percentage of $26.0 \%$, $24.0 \%, 78.0 \%$ and $73.7 \%$ respectively ("ASEAN Guideline on Off-grid Rural Electrification Approaches," 2013). Despite the low electrification percentage, current statistics indicated an exponential increase in energy supply since 2005 with the implementation of new policies, strategies and sharing experiences among ASEAN countries. One of the methods is the use of appropriate technology solutions to suit local condition, environment and resources. With that in mind, the main philosophy of rural electrification has been to provide cost effective and technical support, appropriate for remote isolated places.

The traditional way to generate electricity for rural areas is by extending the existing national grid through distance and hilly terrain and this is prohibitively expensive. On the other hand, decentralized electric generation by building an off grid power generation system using diesel generators, solar power, wind power, biomass, hydropower or a hybrid system is increasingly being recognized and accepted. Considerable numbers of off-grid projects have been reported and highlighting the benefit and challenges faced by any types of power generation sources (Anyi, Kirke, \& Ali, 2010; McNish, Kammen, \& Gutierrez, 2010; S Murni, Whale, Davis, Urmee, \& Harries, 2010; Sari Murni, Whale, Urmee, Davis, \& Harries, 2012). In many cases, it has become clear that microhydro is a favourable source of energy, if there is a potential site. With careful design and implementation, the capacity factor of a microhydro system can reach up to $50 \%$, beyond other types of renewable energy (Uhunmwangho \& Okedu, 2009).

Electrification of rural area using microhydro is considered as most reliable technology to replace the traditional diesel generator. However the high capital cost always an overriding issue in implementing microhydro projects. Capital costs for microhydro scheme are site specific and vary from site to site. The average microhydro scheme has been found to be USD3000/kW(Kennas \& Barnett, 2000; Vaidya) worldwide, on the contrary, the average capital cost for microhydro in Sabah and Sarawak was reported of about USD10,000 / kW (McNish et al., 2010). The high cost was reported mainly come from logistic factor due to remote sites. Typically, a microhydro project is built by appointing contractors or non-government agencies, involving professional consultant services and exponentially increasing the cost.

The main components that comprise the high capital cost of typical microhydro schemes are electromechanical components, civil works and energy distribution system(Arriaga, 2010; Vaidya). An optimum design and smart selection of main components can lower the total cost (Alexander \& Giddens, 2008; Mishra, Singal, \& Khatod, 2011). It is important to pay attention to reducing the overall microhydro cost, because it is always an overriding issue for small communities, consequently making it an unpopular choice.

Electromechanical components cost is site specific but it usually contributes $1 / 3$ of the total cost of microhydro systems. Commercially available turbine offer high efficiency operation, however, they are too expensive and unaffordable for self-funded projects. It is worth to mention that the earnings of rural communities in Borneo are traditional farming and fishing thus economic feasibility is one of the main concerns. The use of PAT for microhydro offers low capital cost as a substitution for a commercial microhydro turbine. Domestic and industrial centrifugal pumpsare readily available and mass produce, thus easy to get in 
hand. Moreover, know-how knowledge operates and maintain a typical end suction pump will reduce technical dependence on expert consultant thus further reduces the cost.

In terms of economic evaluation, Life Cycle Cost Analysis and Rate of Return are a management tools that can help users to select the best choice between two or more products. Overall cost and energy return throughout the equipment life span are carefully determined and compare(Motwani, Jain, \& Patel, 2013). A clear understanding of all cost components throughout lifespan will help project managers to make a sensible selection rather than comparing the capital purchase price.

\section{Research Methodology}

This case study examines the Life Cycle Cost and Rate of Return of using the Pump as Turbine and Multi Jet Pelton for electromechanical components in a micro project. The selection of the turbine is based on potential microhydro site in Kampung Longkongungan, Penampang, Sabah (550'46"N 116 19'31"E). The design is based on hydrology studies in the dry season on August 2012. The potential site has been selected within a radius of 500 meters from school and community hall, after consideration of accessible distance to the powerhouse for routine maintenance. The available head is recorded 22 meters, with $7.55 \%$ slope at the steepest section of the stream with a flow rate of 1001/s.

It is important to highlight that not all available head and flow of the stream is directly converted to usable energy. There are losses of energy between water intake and the power house. Furthermore, less than $40 \%$ of the river capacity can be used after considering irrigation for agricultural activity.

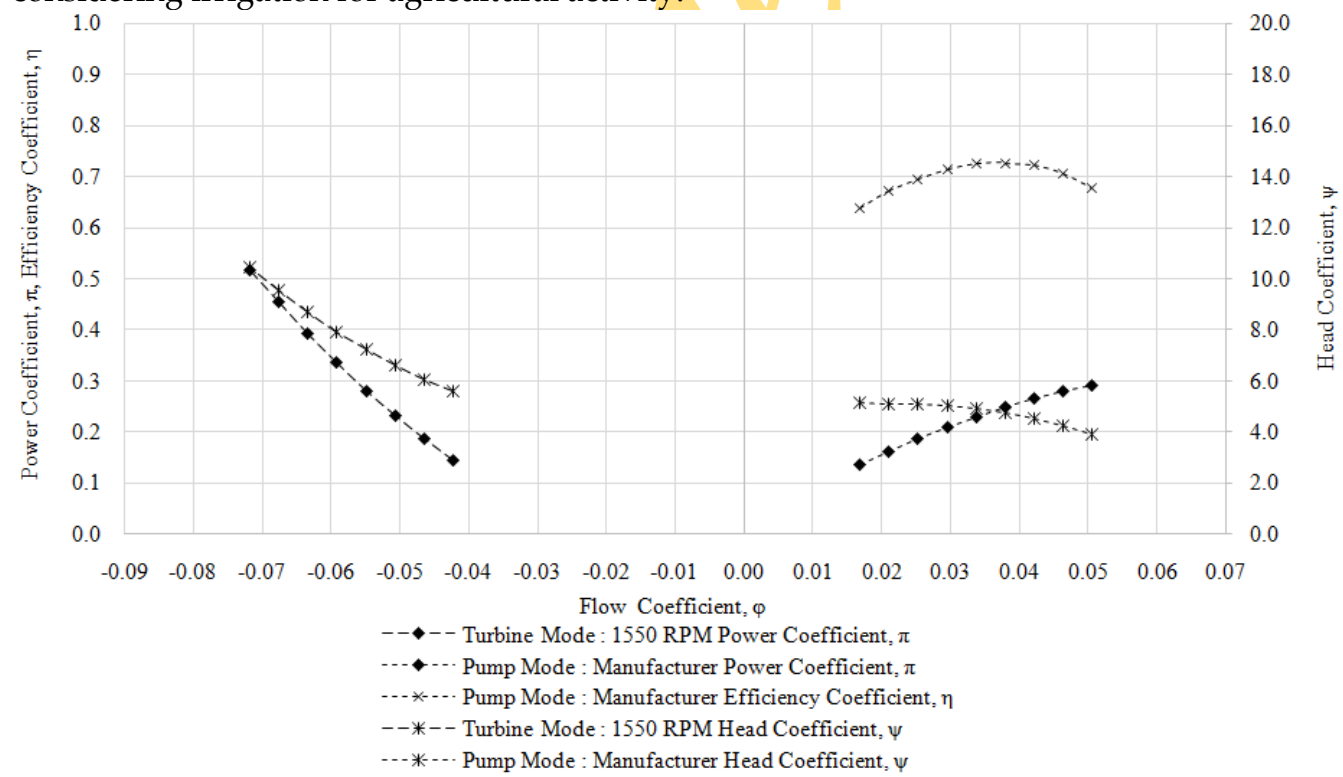

Figure 1: Pump as Turbine Performance Curve

\section{INSTALLATION, SETUP AND OpERATION CONSIDERATION AND LIMITATION}

In this case study, we are only considering electromechanical components. Both turbines are assumed to operate at optimum operating; 18 meters of head and 12 litre/secproduce alternating current at $220 \mathrm{~V}$ with an electric generator with respect to individual performance efficiency. 
Pump as Turbine is coupled with induction generator and use an induction generator controller with ballast load to maintain power quality generated at the terminal. Figure 1 shows the performance curve from simulation result of an end suction centrifugal pump (Euroflo, Model EU50-20). The best efficiency point is recorded at 56\% (Ismail, Othman, \& Zen, 2014).

Multi Jet Pelton Turbine is direct coupled to Permanent Magnet Alternator (PMA) with built in voltage regulator. The system generates good power quality and require minimum technical know-how skill to operate, suitable for remote areas. Due to no local microhydro manufacturer, the Multi Jet Pelton Turbine will be purchased from international supplier.

Table I: Turbine operation characteristic

\begin{tabular}{lccc}
\hline Turbine Operating Specification & Units & $\begin{array}{c}\text { Pump as Turbine } \\
(\text { EU50-20) }\end{array}$ & $\begin{array}{c}\text { Multi Jet Pelton Turbine } \\
\text { (XJ25-3.0kW) }\end{array}$ \\
\hline Potential accessible hydraulic power & $\mathrm{kW}$ & 3.0 & 3.0 \\
Specific Speed, Ns & $\%$ & 70 & 75 \\
Efficiency & & 56 & 80 \\
Capacity Factor & years & 0.4 & 0.4 \\
Life Span & $\mathrm{kg}$ & 48.0 & 15 \\
Weight & $\mathrm{kWh}$ & 5806.08 & 138.0 \\
Annual energy production & $\mathrm{man}$ & 8294.4
\end{tabular}

Table I shows the operational characteristics associated with the choice of electromechanical components. The efficiency of PAT is recorded at lower rate due to poor hydraulic performance, but overcome by low capital cost. On the other hand, Multi Jet Pelton Turbine runs at $80 \%$ with higher capital cost. The life span for both turbines has been set to 15 years with a capacity factor of 0.4 units, which is typical for small-scale hydropower(Akella, Saini, \& Sharma, 2009). The operating condition characteristic isused to calculate annual energy production in $\mathrm{kWh}$.

\section{Economic Evaluation Parameters}

Life Cycle Cost Analysis is an engineering economic analysis tool that covers wider perspective by accounting factors beyond capital cost of a system. The economic evaluations of purchasing and maintaining cost coupled with energy return is essential to determine which system produced the best return on investment. The data in Table II is used to design average life cycle cost for both systems. The total cost expressions include cost to purchase and maintain the system during its lifetime. The annual energy return is also included in this analysis, in order to measure the Rate of Return for both systems.

Table II: Life cycle cost of Pump as Turbine and Multi Jet Pelton Turbine

\begin{tabular}{lrr}
\hline \multicolumn{1}{c}{ Life cycle cost } & $\begin{array}{r}\text { Pump as Turbine } \\
(\text { EU50-20) }\end{array}$ & $\begin{array}{r}\text { Multi Jet Pelton Turbine } \\
(\text { XJ25-3.0kW) }\end{array}$ \\
\hline $\begin{array}{l}\text { Capital cost } \\
\text { Turbine and generator }\end{array}$ & (MYR 3,365.00) & (MYR 6,355.20) \\
Induction Generator Controller & (MYR 1,000.00) & 0.00 \\
Capacitor & (MYR 200.00) & 0.00 \\
Ballast Load & (MYR 500.00) & 0.00 \\
Logistic & 0.00 & (MYR 2,208.00) \\
Import dutyand port clearance (30\%) & 0.00 & (MYR 2,568.96) \\
Annual Energy Return & & \\
Based on local tariff & MYR 1,809.71/year & MYR 2,928.48/year \\
Maintenance Cost & & \\
Greasing moving parts & (MYR 100.00/year) & (MYR 100.00/year)
\end{tabular}




Replace worn parts $\quad$ (MYR 300.00/3 years) (MYR 200.00/3 years)

\section{Capital Cost}

Pump as Turbine capital cost includes the turbine set, Induction Generator, Induction Generator Controller, Ballast Load, and Capacitor Bank. All components that make a complete turbine system are purchased locally, therefore excluding the cost of freight and import duty. The Multi Jet Pelton Wheel is purchased from international suppliers. The capital cost acquiring a complete turbine system includes freight charges at the rate of MYR $16.00 / \mathrm{kg}$. On top of that, the import duty and port clearance are charge at the rate of $30 \%$.

\section{Maintenance Cost}

Maintenance and repair cost covers consumable items relevant to preventive maintenance and repair of the electromechanical system. The preventive maintenance includes both routine housekeeping and lubricating moving parts, such as bearings, which in turn maintain optimum operating performance and extend lifespan. The scheduled maintenance includes replacing worn parts such as nozzle, impeller and bearings. In terms of repair, replacing parts is carried out based on operation and maintenance manuals for both systems.

\section{Energy Revenue}

The energy return on the installed systems is measured by converting it to revenue in term of MYR (Malaysia Ringgit) based on Sabah Electric Sdn. Bhd. (SESB) domestic tariff rate. It is important to mention that electricity power in Sabah is partly subsidized by the government, which has a low power tariff among Asia-Pacific countries

\section{Present Value (PV)}

Present value illustrates practical analysis when using currency to measure future cash flow. The calculation using Present Value is appropriate because the analysis considers an investment projection of 15 years life span. For this case study, the discounted rate is set at $5 \%$ per annum.

\section{RESULTS AND Discussion}

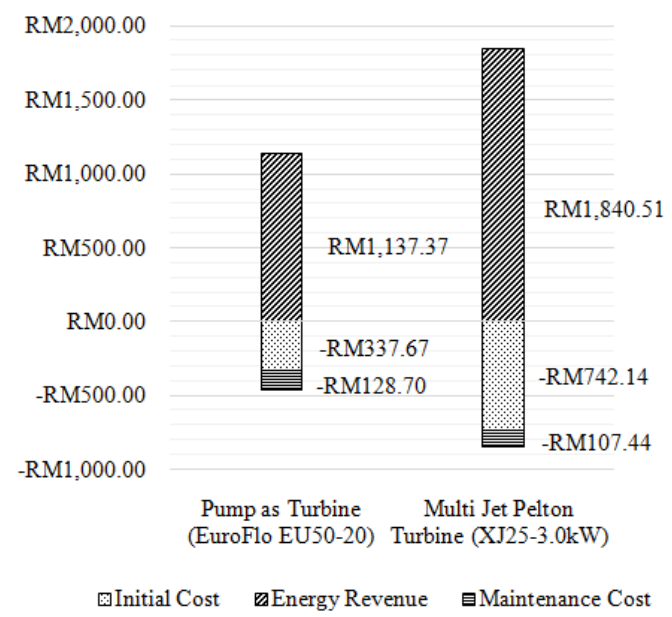

(a)

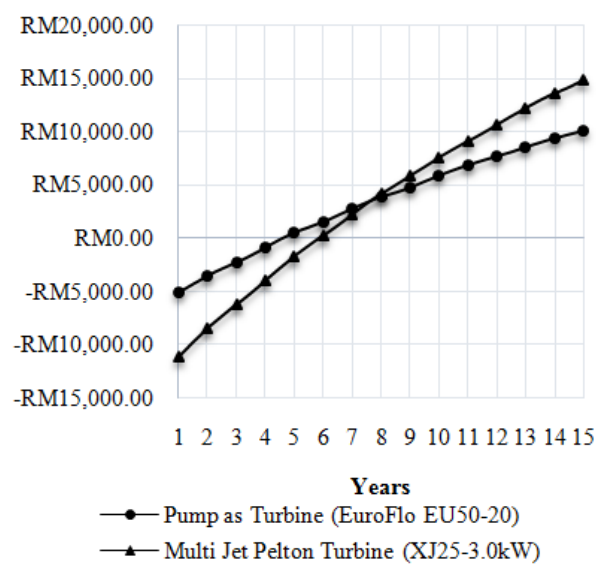

(b) 
Figure 2: (a) Annual life cycle cost for PAT and Multi Jet Pelton(b) Cash Flow for PAT and Multi Jet Pelton

Once the present values of all costs and return have been recognized, the annual life cycle cost is accomplished by adding together all the costs and revenue to single amount and divided by the number of life span. The annual life cycle cost of both choices as an electromechanical component in microhydro systems are shown in Figure 2 (a). The total annual net revenue for Pump as Turbine and Multi Jet Pelton Turbine has been recorded at MYR671.00 and MYR990.93, respectively. The annual capital cost for Multi Jet Pelton is significantly higher than Pump as Turbine. The reason of this is from surplus purchasing cost imposed such as freight charges, import duty and port clearance explained earlier in this paper. The annual maintenance cost between both systems is recorded at MYR128.70 and MYR107.44. The Multi Jet Pelton generatesa higher energy return annually since it has higher efficiency. The cash flow of the Pump as Turbine and Multi Jet Pelton Turbine is shown in Figure 2 (b). The Rate of Return for Pump as Turbine and Multi Jet Pelton Turbine is recorded at 4.34 years and 6.11 years respectively. The Pump as Turbine has lower Rate of Return, however lower cumulative profit at MYR 10,065.11 after 15 years. On the other hand, Multi Jet Pelton turbine has longer Rate of Return, but the cumulative profit has been recorded at MYR 14,863.82 with higher return of investment.

\section{CONCLUSION}

This case study is intended to show an economic evaluation as one of decision tools to help project managers to choose most economical choices between two or more options. With that in mind, economic evaluations consisting of Life Cycle Cost Analysis and Rate of Return for electromechanical components for Kampung Longkongungan, Sabah, were analysed and compared. All relevant costsoverthe electromechanical operation life span were grouped in three distinct elements, namely capital cost, maintenance cost and energy revenue. The result shows that Pump as Turbine has a low capital cost and shorter Rate of Return. However, due to low efficiency, thetotal return of investment is lower than Multi Jet Pelton Turbine. It is worth to mention that, high capital investment is always an overriding issue for a small community project. However, if there is adequate funding, Multi Jet Pelton Turbine is the best choice forelectromechanical components.

\section{REFERENCE}

Akella, A. K., Saini, R. P., \& Sharma, M. P. (2009). Social, Economical and Environmental Impacts of Renewable Energy Systems. Renewable Energy, 34(2), 390-396.

Alexander, K. V., \& Giddens, E. P. (2008). Microhydro: Cost-effective, modular systems for low heads. Renewable Energy, 33(6), 1379-1391. doi: 10.1016/j.renene.2007.06.026

Anyi, Martin, Kirke, Brian, \& Ali, Sam. (2010). Remote Community Electrification in Sarawak, Malaysia. Renewable Energy, 35(7), 1609-1613.

Arriaga, Mariano. (2010). Pump as Turbine - A Pico-Hydro Alternative in Lao People's Democratic Republic. Renewable Energy, 35(5), 1109-1115.

ASEAN Guideline on Off-grid Rural Electrification Approaches. (2013). In A. C. f. Energy (Ed.).

Ismail, Mohd Azlan, Othman, Al Khalid, \& Zen, Hushairi. (2014). Numerical Simulation on End Suction Centrifugal Pump Running in Inverse Flow for Microhydro Applications. Paper presented at the International Integrated Engineering Summit Malaysia. 
Asia Pacific Journal of Energy and Environment, Volume 2, No 1 (2015)

Kennas, Smail, \& Barnett, Andrew. (2000). Best Practices for Sustainable Development of Micro Hydro Power in Developing Countries.

McNish, Tyler, Kammen, Daniel M., \& Gutierrez, Benjamin. (2010). Clean Energy Options for Sabah: An Analysis of Resource Availability and Cost.

Mishra, Sachin, Singal, S. K., \& Khatod, D. K. (2011). Optimal Installation of Small Hydropower Plant-A Review. Renewable and Sustainable Energy Reviews, 15(8), 3862-3869.

Motwani, K. H., Jain, S. V., \& Patel, R. N. (2013). Cost Analysis of Pump as Turbine for Pico Hydropower Plants - A Case Study. Procedia Engineering, 51, 721-726.

Murni, S, Whale, J, Davis, JK, Urmee, T, \& Harries, D. (2010). Status of Rural Electrification in The 'Heart of Borneo': Role of Micro Hydro Projects.

Murni, Sari, Whale, Jonathan, Urmee, Tania, Davis, John, \& Harries, David. (2012). The Role of Micro Hydro Power Systems in Remote Rural Electrification: A Case Study in The Bawan Valley, Borneo. Procedia Engineering, 49(0), 189-196.

Uhunmwangho, R., \& Okedu, E.K. (2009). Small Hydropower for Sustainable Development. Pacific Journal of Science and Technology, 10(2), 535-543.

Vaidya, Dr. Cost and Revenue Structures for Micro-Hydro Projects in Nepal. http://www.microhydropower.net/download/mhpcosts.pdf

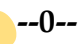




\section{ACKNOWLEDGEMENT}

This research was supported by the Centre of Excellence for Renewable Energy (CoERE), Universiti Malaysia Sarawak (UNIMAS) under Grant no. UNIMAS/CoERE/2014/Grant (01). 